\title{
Tempo e Grau de dificuldade como Critérios de Rateio dos Custos Indiretos na Produção de Móveis sob Medida
}

\author{
Ana Paula Stuhlert \\ Pós-Graduação em Gestão de Custos pelo Centro Universitário para o \\ Desenvolvimento do Alto Vale do Itajaí - UNIDAVI \\ Auxiliar Contábil \\ Campus Universitário. Trindade. Centro Socioeconômico. Florianópolis/SC. CEP: \\ 88040-970 \\ E-mail: anapstuhlert@gmail.com
}

\begin{abstract}
Altair Borgert
Doutorado em Engenharia de Produção pela Universidade Federal de Santa Catarina - UFSC

Professor na Universidade Federal de Santa Catarina - UFSC Campus Universitário. Trindade. Centro Socioeconômico. Florianópolis/SC. CEP: 88040-970 ORCID: https://orcid.org/0000-0002-0116-8089 E-mail: altair@borgert.com.br
\end{abstract}

Emanuele Engelage Doutoranda em Contabilidade pela Universidade Federal de Santa Catarina - UFSC Integrante do Grupo de Gestão de Custos (GGC) do Programa de Pós-Graduação em Contabilidade (PPGC) da Universidade Federal de Santa Catarina - UFSC Campus Universitário - Trindade, Centro Socioeconômico, Bloco C, Sala 218, Florianópolis, Santa Catarina - SC, CEP: 88040-970 ORCID: https://orcid.org/0000-0002-9243-5209

E-mail: manuengelage@hotmail.com

\section{RESUMO}

Este estudo objetivou analisar se a atribuição de pesos por grau de dificuldade pode ser considerado um critério válido para rateio dos custos indiretos de produção, comparativamente ao tempo de fabricação, por meio de estudo de caso numa microempresa fabricante de móveis sob medida. A coleta de dados ocorreu mediante verificação documental, observação não participante e indagações diretas ao sócio proprietário e sua equipe. Para as análises, aplicou-se o modelo de Custeio por Absorção, cujos resultados indicam que nos meses analisados houve variação dos custos atribuídos a cada móvel fabricado, em função dos critérios adotados, mas para os projetos individualmente essa variação não é superior a 11,6\%. Também, manteve-se a ordem de produtos com mais custos indiretos, tanto em valores absolutos quanto percentuais, o que sugere pouca variabilidade financeira entre os critérios e demonstra que o conhecimento do proprietário quanto à complexidade do processo produtivo (grau de dificuldade) pode ser considerado um parâmetro válido para apropriação dos custos indiretos dentro do Custeio por Absorção. Contudo, houve maior dificuldade de operacionalização pelo tempo de fabricação, devido à necessidade contínua de anotações. Indiferente do critério adotado, os preços de venda praticados permitem uma lucratividade alinhada às expectativas do gestor, 
Tempo e Grau de dificuldade como Critérios de Rateio dos Custos Indiretos na Produção de Móveis sob Medida

Ana Paula Stuhlert, Altair Borgert, Emanuele Engelage

sendo que, segundo ele, ambas as técnicas fornecem base informacional para melhorar a tomada de decisão.

Palavras-chave: Custeio por Absorção. Custos Indiretos. Grau de dificuldade. Esforço de produção. Móveis sob medida.

\title{
Time and difficulty Level as Criteria for Apportioning Indirect Costs of Custom
} Furniture Production

\begin{abstract}
This study aimed to analyze if the allocation of weight criteria by difficulty level can be considered a valid criterion for indirect cost rate of production, compared to the time of manufacture. Through a case study in a small company that manufactures custommade furniture, the data collection occurred with a documentary verification, a nonparticipant observation, and direct inquiries to the owner partner and his team. For the analyzes, the Absorption Costing model was applied, whose results indicate there was a variation in the costs attributed to each furniture manufactured, according to the adopted criteria in the months under analyzis, but for individual projects it was not higher than $11.6 \%$. Also, the order of products with more indirect costs was maintained both in absolute and percentage values, which suggests a little financial variability between the criteria, and demonstrates that the owner's knowledge of the complexity of the production process (difficulty level) can be considered a valid parameter for the appropriation of indirect costs within Absorption Costing. However, there was difficulty in operationalization due to the time of manufacture, owing to the continuous need for records. Regardless of the adopted criterion, the practiced sales prices allow a profitability aligned with the manager's expectations, and, according to him, both techniques provide an informational basis to improve decision making.
\end{abstract}

Keywords: Absorption costing. Indirect costs. Difficulty level. Production effort. Custom-made furniture.

Tiempo y Grado de Dificultad como Criterios para Prorrateo de los Costos Indirectos en la Producción de Muebles Personalizados

\section{RESUMEN}

Este estudio tuvo como objetivo analizar si la asignación de pesos por grado de dificultad puede considerarse un criterio válido para prorratear los costos indirectos de producción, en comparación al tiempo de fabricación, a través de un caso de estudio en una microempresa de muebles a medida. La recolecta de datos ocurrió a través de verificación documental, observación no participante y consultas directas al socio propietario y su equipo. Para los análisis se aplicó el modelo de Costo de Absorción, cuyos resultados indican que en los dos meses analizados hubo una variación en los costos atribuidos a cada mueble fabricado, según los criterios adoptados, pero para los proyectos individuales no es superior a 11,6\%. Asimismo, se mantuvo el orden de productos con más costos indirectos, tanto en valores absolutos como porcentuales, lo que sugiere poca variabilidad financiera entre los 
criterios y demuestra que el conocimiento del propietario de la complejidad del proceso de producción (grado de dificultad) puede considerarse un parámetro válido para la apropiación de costos indirectos dentro del Costeo de Absorción. Sin embargo, hubo una mayor dificultad en la operatividad debido al tiempo de fabricación, debido a la continua necesidad de anotaciones. Independientemente del criterio adoptado, los precios de venta practicados permiten una rentabilidad acorde a las expectativas del gerente y, según él, ambas técnicas brindan base informativa para mejorar la toma de decisiones.

Palabras clave: Costeo por absorción. Costos indirectos. Nivel de dificultad. Esfuerzo de producción. Muebles a medida.

\section{INTRODUÇÃO}

Dentre as estratégias adotadas pelas empresas como resposta a um mercado altamente competitivo e exigente está a precificação, em função da sensibilidade da maior parte das atividades sobre esse aspecto (Pinto \& Moura, 2011). Nesse contexto, o conhecimento dos custos propicia maior segurança aos tomadores de decisão por auxiliar o planejamento e o controle e fornecer indícios sobre fatores de ineficiência, suas motivações e possibilidades de aperfeiçoamento, para que se possa ter margem para trabalhar o preço de venda (Borgert \& Silva, 2005).

Os custos de uma empresa, por serem a combinação de diversos fatores, precisam ser estruturados por meio de um método de custeio (Bornia, 2002). Para tanto, existem diversos modelos que podem ser aplicados, dentre os quais: Custeio Variável, ABC (Activity Based Costing), Custeio por Absorção e Método da UEP (Unidade de Esforço de Produção). Cada um possui vantagens e desvantagens quanto à sua aplicação, sendo necessário analisar o perfil da empresa e seus principais objetivos para determinar o modelo que melhor atenda aos seus interesses (Abbas, Gonçalves \& Leoncine, 2012).

Um modelo já consolidado e amplamente utilizado no Brasil é o Custeio por Absorção, cuja principal vantagem é o fato de segregar os gastos empresariais entre custos e despesas, o que permite a sua utilização tanto para fins gerencias quanto para mensuração de estoque e outros aspectos fiscais. Além disso, a implantação do Custeio por Absorção requer menos recursos financeiros e de pessoal se comparado a outros modelos, como o ABC, que, apesar de gerar informações mais detalhadas, tem aplicação mais complexa e custosa (Schultz, Silva, \& Borgert, 2010). 
Outro que, mais recentemente, tem ganhado espaço nas empresas e nas discussões acadêmicas é a UEP. De acordo com Belli, Andruchechem, Richartz e Borgert (2013), enquanto alguns modelos de custeio se atentam para a alocação dos custos indiretos aos produtos geralmente com base nos gastos com mão de obra, no consumo de matéria-prima ou no tempo de produção, a UEP foca na análise dos custos de transformação, ao criar uma unidade de medida homogênea para o cálculo do custo e a mensuração de produções diversificadas.

Contudo, tanto o Custeio por Absorção quanto a UEP acabam por receber algumas críticas. No caso do primeiro, sobretudo, questiona-se a arbitrariedade na definição dos critérios de rateio utilizados para apropriação dos custos indiretos aos produtos (Schultz et al., 2010). Já, no segundo, destacam-se como fatores restritivos o uso apenas dos gastos de transformação, por não mensurar custos de aquisição de materiais diretos e não identificar possíveis melhorias (Bornia, 2002).

Diante desse contexto, uma alternativa viável para as empresas é promover a integração de aspectos metodológicos ou conceituais desses diferentes modelos (Belli et al., 2013). Estudos como o de Borgert e Silva (2005) e Belli et al. (2013) atuam de forma híbrida, ao combinar a aplicação de modelos de custeio distintos. Os autores alegam que, dessa forma, consegue-se unir pontos favoráveis como, por exemplo, o detalhamento do $A B C$ com a agilidade e a praticidade da UEP, o que simplifica a mensuração dos custos.

Contudo, indaga-se se é preciso, necessariamente, utilizar tais métodos de forma completa e integral, como realizado por autores que propõem metodologias híbridas (Borgert \& Silva, 2005; Machado, Borgert, \& Lunkes, 2006; Silva, Borgert, \& Schultz, 2009; Belli et al., 2013; Freitas, Borgert, \& Flach, 2016). Isso porque, ao considerar os fatores restritivos acima mencionados, a busca por formas de rateio dos custos indiretos que considerem, também, perspectivas comportamentais, como a percepção dos usuários sobre os esforços de produção, pode fundamentar e justificar o uso para além do Custeio por Absorção, tornando-se uma alternativa aos critérios tradicionais, julgados arbitrários e que demandam um controle mais rígido.

Dessa forma, a presente pesquisa propõe a combinação de aspectos conceituais do método UEP com os aspectos metodológicos do Custeio por Absorção, ao estabelecer a seguinte questão de pesquisa: a utilização do grau de dificuldade atribuído a cada peça fabricada é um critério de rateio válido para a 
apropriação dos custos indiretos de produção de móveis sob medida, se comparado ao tempo de fabricação?

Para responder esse questionamento, objetiva-se analisar se a atribuição de pesos por grau de dificuldade pode ser considerado um critério válido para rateio dos custos indiretos de produção, comparativamente ao tempo de fabricação. Assim, no sentido de contribuir com as limitações da aplicação do Custeio por Absorção, identifica-se o custo de fabricação de móveis sob medida de uma microempresa localizada na cidade de Rio do Sul, em Santa Catarina, e comparam-se dois critérios de rateios para os custos indiretos: (i) tempo de fabricação de cada móvel, que é considerado um critério usual e já consolidado na literatura (Belli et al., 2013); e (ii) grau de dificuldade atribuído a cada peça fabricada, que deriva da lógica UEP, cuja base conceitual é a equivalência (Levant \& Zimnowitch, 2013). Enfim, analisa-se a existência ou não de diferenças substanciais desses dois critérios, tanto nos custos/valores encontrados quanto na dificuldade percebida pelo gestor em termos de aplicação prática e sua contribuição para a tomada de decisão.

Os resultados deste estudo têm implicações teóricas e práticas. No aspecto teórico tem-se um avanço nos estudos da área de gestão de custos por dar enfoque às empresas de produção sob encomenda, sobretudo quanto à apresentação de uma forma alternativa de rateio dos custos indiretos em modelos de custeio já concebidos. Ao identificar as similaridades e diferenças deste com critérios mais usuais, pode-se verificar se o conhecimento dos gestores e dos usuários sobre sua atividade, relacionado à sua percepção sobre os esforços de produção, é um critério de rateio válido e se o mesmo reduz as desvantagens quando da utilização do Custeio por Absorção. Ainda, conforme Severiano Filho e de Melo (2006), a busca por formas alternativas de rateio dos custos indiretos ganha relevância, ao passo que esse é o foco das críticas recebidas pelo método, pois essa escolha pode distorcer resultados, penalizar alguns produtos e beneficiar outros.

O estudo também apresenta contribuições práticas, visto que os dados apurados possibilitam ao empresário a visualização do seu custo de produção, com base no esforço (grau de dificuldade) e no tempo dedicado a cada produto. Atualmente, a empresa possui controles simplificados e superficiais e a utilização de um modelo de custeio que proporcione relatórios, demonstrativos e análises 
históricas, pode fornecer embasamento e maior segurança para a precificação e a definição de estratégias.

\section{REVISÃO DE LITERATURA}

Para que seja realizada a apuração dos custos de uma empresa é preciso que esses sejam estruturados em um modelo de custeio, haja vista que há uma variedade de parâmetros que podem ser utilizados, em especial para apropriação de custos indiretos, os quais requerem direcionadores e critérios de alocação, pois sua distribuição aos produtos não é tão clara e precisa quanto os custos diretos (Rabelo, Borgert, \& Medeiros, 2009; Hojna \& Stryckova, 2018).

A presente pesquisa utiliza-se dos parâmetros metodológicos do Custeio por Absorção, o qual realiza a apropriação dos custos indiretos aos produtos e/ou serviços através de rateios (Schultz et al., 2010). Apesar de sofrer críticas quanto a possível arbitrariedade na escolha desses critérios, esse modelo ainda é amplamente utilizado, pois se caracteriza pela separação entre os custos e as despesas e, portanto, além de sua utilidade gerencial, no Brasil, também, é aceito pelo fisco para fins de mensuração de estoques (Schultz et al., 2010).

Segundo Neves e Viceconti (2003), o Custeio por Absorção tem os seguintes procedimentos básicos: (i) separação de custos e despesas; (ii) apropriação dos custos diretos e indiretos à produção realizada no período; (iii) apuração do custo da produção acabada; (iv) apuração do custo dos produtos vendidos; e (v) apuração do resultado. De acordo com Abbas et al. (2012), outra maneira de apurar o custo pelo Custeio por Absorção é por meio da departamentalização, em que divide a empresa em departamentos auxiliares e principais. Inicialmente, os custos indiretos são alocados aos departamentos auxiliares e, desses, transfere-se aos principais. Por fim, realiza-se o rateio dos custos aos produtos ou serviços, geralmente pelo tempo de passagem pelos departamentos.

O Custeio por Absorção é considerado um modelo consolidado e amplamente utilizado, visto que possui vantagens como: o atendimento à legislação fiscal; a integração aos sistemas contábeis; a apuração do custo por centro de custos; e a identificação do custo total de cada produto por absorver todos os gastos de produção (Severiano Filho \& de Melo, 2006). Dada sua relevância prática, o modelo 
tem servido como base para muitos estudos empíricos, sem perder sua prestabilidade ao longo do tempo. A exemplo, têm-se as pesquisas de De Lima e Thomaz (2020) e Martins e Miranda (2020) realizadas recentemente no Brasil.

De Lima e Thomaz (2020) utilizaram o Custeio por Absorção para apurar os custos dos serviços de tomografia de um hospital localizado no Vale do Paranhana, no Rio Grande do Sul. Após identificá-los, os autores confrontaram os custos dos procedimentos/exames com os repasses realizados pelo Sistema Único de Saúde (SUS) e constataram que a remuneração conforme tabela do SUS causa perda financeira à instituição. Por sua vez, Martins e Miranda (2020) utilizaram o Custeio por Absorção para identificar os custos de produção do pão francês de uma padaria situada no bairro Vila Maria, em Aparecida de Goiânia, Goiás.

Em âmbito internacional, Hojna e Stryckova (2018) fornecem evidências atualizadas sobre o uso do Custeio por Absorção em empresas de manufatura da República Tcheca. Os autores aplicaram um questionário para identificar os critérios de rateio mais utilizados por essas empresas, onde se destaca a técnica baseada no cálculo das taxas gerais/cotações.

Ainda, com enfoque nos critérios de rateio, Faria et al. (2020) realizaram uma pesquisa de múltiplos casos em empresas brasileiras do setor industrial, comercial e de prestação de serviços, a fim de discutir os modelos de estimação adotados (dentre os quais está o Absorção) e analisar as formas de apropriação dos custos indiretos aos projetos dessas empresas. Os autores constataram que projetos com maior detalhamento do escopo mostram menor dificuldade para identificação de custos indiretos, o que influencia no modelo de custeio adotado. Já, na apropriação desses custos, há particularidades entre os casos, mas com objetivos semelhantes em sua incorporação, baseando-se, principalmente, nas horas de trabalho.

Contudo, pode-se utilizar inúmeros outros critérios de rateio, desde que representem da maneira mais assertiva possível a realidade organizacional. Nesse sentido, a presente pesquisa utiliza, além do fator "tempo" citado por Abbas et al. (2012) e por Faria et al. (2020), o fator "grau de dificuldade", que visa captar a percepção do gestor sobre seu negócio por meio do esforço de produção, num sentido mais amplo, cujo critério deriva da concepção do método da UEP.

Segundo Morozini, Cambruzzi e Balen (2009), esse modelo se baseia no estabelecimento de uma unidade de medida para mensurar a produção de toda a 
fábrica. Isso porque cria uma proporção entre os diversos processos produtivos e esforços de produção utilizados para a fabricação do produto ou realização de determinado serviço. Assim, a UEP cria uma unidade de medida que agrupa e quantifica produtos e serviços distintos que utilizam os mesmos esforços, porém com intensidade diferente, simplificando a mensuração dos custos e seu controle (Borgert \& Silva, 2005). Esse método parte do princípio que durante os processos de transformação da matéria-prima agrega-se valor à produção por meio dos esforços realizados, os quais devem ser mensurados, criando-se uma unidade de medida comum entre a produção diversificada de uma empresa (Morozini et al., 2009).

Diante disso, o presente estudo, apesar de não utilizar o método UEP, mas sim o Custeio por Absorção, apropria-se da concepção mencionada por Morozini et al. (2009) de que os esforços realizados agregam valor ao processo produtivo e, portanto, podem representar um fator importante para o rateio dos custos indiretos.

Diversos estudos abordam a união de métodos de custeio, com vistas a suprir as críticas recebidas e extrair o melhor de cada um. De acordo com Borgert e Silva (2005), sempre é possível melhorar um modelo de custeio, haja vista que "é uma simplificação da realidade" (Bornia, 2002, p. 46). Contudo, a maioria dos estudos atuam de forma híbrida, ao integrar, também, seus aspectos metodológicos. Tem-se como exemplo os estudos de Borgert e Silva (2005), que analisou uma empresa prestadora de serviços no segmento de beleza; Machado et al. (2006), que focou numa empresa desenvolvedora de softwares; Silva et al. (2009), que custeou procedimentos médicos em organizações hospitalares; Belli et al. (2013), que aplicou a uma empresa prestadora de serviços de colheita florestal; e Freitas et al. (2016), que analisou uma empresa australiana que opera em modalidade de home office.

Inicialmente, tais estudos alocaram os custos por meio do $A B C$, posteriormente, implantaram a UEP para simplificação do cálculo e gestão do processo produtivo. Dessa forma, pode-se disponibilizar informações relevantes aos gestores através de processos simples que dispensam recursos tecnológicos sofisticados e permitem o rastreamento de operações e a simplificação e padronização do custeio (Borgert \& Silva, 2005).

Contudo, apesar do presente estudo não propor a aplicação integral do método UEP, como nas pesquisas mencionadas, utiliza-se a lógica da equivalência 
baseada em esforço de produção como critério de rateio para os custos indiretos. Assim, mantem-se o uso do Custeio por Absorção, mas integra-se os conceitos e a lógica da UEP como forma alternativa de análise, a fim de gerar comparabilidade do custo calculado pelos tempos de produção.

\section{PROCEDIMENTOS METODOLÓGICOS}

Esta pesquisa refere-se a um estudo de caso, e analisa os custos de móveis sob medida fabricados numa empresa específica, localizada na cidade de Rio do Sul, em Santa Catarina. Para Yin (2005), o estudo de caso é uma investigação empírica que analisa um fenômeno contemporâneo dentro de seu contexto da vida real.

A empresa em questão iniciou suas atividades em 2004, quando o proprietário, que na época era funcionário de outra empresa, começou a fabricar móveis sob medida em seus finais de semana. Com o tempo, conseguiu adquirir maquinários e ferramentas e aumentar a demanda de serviço, em especial pela indicação de clientes. Em outubro de 2009, começou a se dedicar integralmente à marcenaria e, em 2013, formalizou a abertura da empresa. Atualmente, além do sócio proprietário, que também é marceneiro, a empresa conta com mais dois funcionários: um auxiliar de marcenaria e um auxiliar de escritório, sendo que a contabilidade é terceirizada. A principal região atendida é a do Alto Vale do Itajaí, mas há clientes em algumas cidades do litoral norte, como Navegantes, Itapema e Balneário Camboriú.

Dadas as características da empresa, como primeira etapa de pesquisa, identificou-se junto ao sócio proprietário informações relativas ao seu processo produtivo, como os principais tipos e formatos de peças utilizadas e os principais recursos e técnicas de fabricação dos móveis. Assim, elaborou-se um fluxograma para nortear a coleta e a análise de dados.

Na presente pesquisa utilizou-se tanto dados primários quanto secundários. Os primários são aqueles ainda não coletados, pesquisados com o objetivo de atender as necessidades específicas da pesquisa que, neste caso, são os dados de "tempo" e "grau de dificuldade" de cada fase do processo produtivo. Por outro lado, os dados secundários são aqueles que já foram coletados, tabulados, ordenados e, 
algumas vezes, até analisados, o que ocorre com os dados de "custos", que já fazem parte dos registros da empresa (Mattar, 2005).

A coleta dessas informações ocorreu por meio de análise documental, observação não participante e indagações diretas, realizadas ao sócio proprietário e à sua equipe. Dentre os documentos fornecidos pela empresa, têm-se notas e cupons fiscais de compra e venda, demonstrações contábeis e planilhas gerenciais que permitem identificar e classificar os custos diretos e indiretos incorridos em cada mês. Além disso, elaborou-se um formulário de preenchimento, utilizado no decorrer dos processos produtivos, que contempla a descrição do tipo de orçamento e as características das chapas de MDF, das peças e dos processos de pré-montagem e montagem. Também, realizou-se anotações de todos os tempos de produção em cada fase de fabricação dos móveis.

Ao tomar por base a média dos tempos cronometrados e as informações repassadas, para a etapa de análise dos dados, primeiramente, atribuiu-se o tempo padrão necessário para confecção de cada peça em cada fase do processo produtivo. Em seguida, partindo-se do princípio da UEP, que durante os processos de transformação da matéria-prima agrega-se valor à produção por meio dos esforços realizados (Morozini et al., 2009), utilizou-se como critério de rateio dos custos indiretos o "grau de dificuldade" de produção. Dessa forma, mensurou-se os esforços utilizados para a fabricação de cada peça, por meio da atribuição de pesos que variam de 1 (mínimo) a 5 (máximo), em observância a lógica da equivalência. Essa classificação foi realizada pelo sócio proprietário em conjunto com o seu funcionário (marceneiro), visto que ambos são os detentores desse conhecimento na empresa, dadas as suas experiências operacionais e técnicas.

Com essas informações e o auxílio do software Microsoft $\circledast$ Office Excel, calculou-se os custos totais (diretos e indiretos) de cada móvel por meio de ambos os critérios de rateio (tempo de fabricação e grau de dificuldade) e, em confronto com os preços de venda, identificou-se os lucros obtidos em cada projeto (móvel). Por fim, realizou-se uma análise comparativa dos resultados financeiros e da perspectiva do gestor quanto às facilidades e dificuldades de implantação do modelo para cada critério de rateio.

Cabe salientar que, em função da acessibilidade e, principalmente, da demanda por anotações específicas, referentes aos dados primários, analisou-se os 
móveis produzidos em outubro de 2018 e janeiro de 2019, sendo esse, também, o período de coleta de dados, cujas análises ocorreram nos meses subsequentes, de fevereiro a maio de 2019.

\section{RESULTADOS}

Diante da crescente competitividade no ramo moveleiro, torna-se necessário obter maior controle da produtividade a fim de mitigar os riscos de inconsistências na elaboração dos orçamentos. Para que isso seja possível, inicialmente, buscou-se conhecer os processos produtivos e, portanto, elaborou-se o fluxograma da empresa, conforme demonstrado na Figura 1, com a especificação de cada processo de fabricação dos móveis, desde o primeiro contato com o cliente até a entrega final.

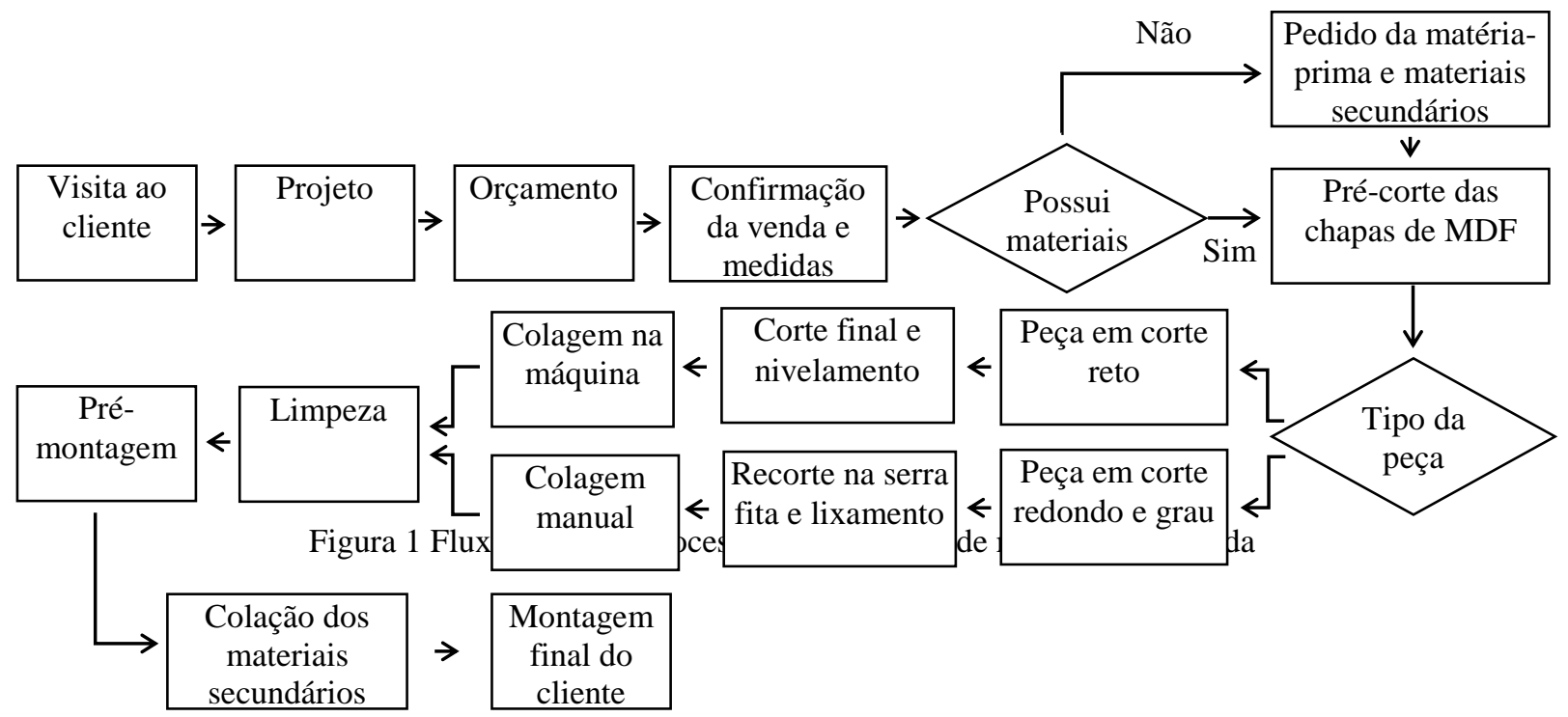

Figura 1. Processo de fabricação dos móveis

Fonte: Elaborado com base nos dados da pesquisa.

Com a identificação desse fluxo, analisou-se as macro etapas do processo produtivo que interferem diretamente no custo do produto: (i) elaboração do orçamento; (ii) corte; (iii) colagem; (iv) limpeza das peças; e (v) pré-montagem na empresa e montagem do móvel no cliente. Com essa definição, por meio de formulário coletou-se os dados com os principais tipos e tamanhos de peças utilizadas para a fabricação de cada móvel, preenchido pelo marceneiro durante o processo fabril, com a especificação de quais tipos de peças são utilizadas, a sua 
Tempo e Grau de dificuldade como Critérios de Rateio dos Custos Indiretos na Produção de

quantidade, a cor da chapa de MDF, a descrição se o projeto é feito pelo próprio marceneiro ou de arquiteto contratado pelo cliente, bem como o tempo gasto para realizar a pré-montagem e montagem do móvel. A Tabela 1 apresenta 0 detalhamento dessas informações para os sete móveis analisados, sendo quatro referentes ao mês de outubro de 2018 (três cozinhas e uma sala) e três referentes a janeiro de 2019 (dois quartos e uma cozinha). 
Tempo e Grau de dificuldade como Critérios de Rateio dos Custos Indiretos na Produção de

Móveis sob Medida

Ana Paula Stuhlert, Altair Borgert, Emanuele Engelage

Tabela 1

Formulário de Outubro de 2018 (10/2018) e Janeiro de 2019 (01/2019)

\begin{tabular}{|c|c|c|c|c|c|}
\hline \multicolumn{6}{|c|}{ Mês Referência: Outubro/2018 } \\
\hline Características & $\begin{array}{l}\text { Projeto 1: } \\
\text { Cozinha }\end{array}$ & $\begin{array}{l}\text { Projeto 2: } \\
\text { Sala }\end{array}$ & $\begin{array}{l}\text { Projeto 3: } \\
\text { Cozinha }\end{array}$ & $\begin{array}{c}\text { Projeto 4: } \\
\text { Cozinha }\end{array}$ & $\begin{array}{l}\text { Total } \\
\text { Mês }\end{array}$ \\
\hline \multicolumn{6}{|l|}{ Tipo do Orçamento } \\
\hline Projeto próprio $(\mathrm{h})$ & $0: 45$ & $0: 35$ & $1: 20$ & $1: 10$ & $3: 50$ \\
\hline $\begin{array}{l}\text { Projeto de arquitetos } \\
\text { Cor da Chapa }\end{array}$ & - & - & - & - & - \\
\hline Chapa cor clara & - & 1 & 1 & - & 2 \\
\hline Chapa cor escura & 1 & - & - & 1 & 2 \\
\hline \multicolumn{6}{|l|}{ Tipo Peças* } \\
\hline Peças retas até $30 \mathrm{~cm}$ & 16 & - & 49 & 59 & 124 \\
\hline Peças retas $30 \mathrm{~cm}$ a $1 \mathrm{~m}$ & 33 & 25 & 69 & 65 & 192 \\
\hline Peças retas $1 \mathrm{~m}$ a $2 \mathrm{~m}$ & 6 & 6 & 4 & 2 & 18 \\
\hline Peças retas acima de $2 \mathrm{~m}$ & - & - & & 4 & 4 \\
\hline Peças em grau de $30 \mathrm{~cm}$ a $1 \mathrm{~m}$ & - & - & 3 & - & 3 \\
\hline $\begin{array}{l}\text { Peças em sequência do desenho da } \\
\text { chapa } 30 \mathrm{~cm} \text { a } 1 \mathrm{~m}\end{array}$ & 4 & - & - & - & 4 \\
\hline $\begin{array}{l}\text { Peças chapa dupla (reforçada) } 30 \\
\mathrm{~cm} \mathrm{a} 1 \mathrm{~m}\end{array}$ & 5 & 9 & 8 & 7 & 29 \\
\hline $\begin{array}{l}\text { Peças chapa dupla (reforçada) } 1 \mathrm{~m} \\
\text { a } 2 \mathrm{~m}\end{array}$ & 1 & 5 & 1 & 1 & 8 \\
\hline $\begin{array}{l}\text { Peças chapa dupla (reforçada) } \\
\text { acima } 2 \text { m }\end{array}$ & 5 & 3 & 5 & 6 & 19 \\
\hline $\begin{array}{l}\text { SUBTOTAL } \\
\text { Pré-Montagem e Montagem }\end{array}$ & 70 & 48 & 139 & 144 & 401 \\
\hline Pré-montagem (empresa) - $\mathrm{h}$ & 7:00 & $4: 30$ & $10: 00$ & $10: 00$ & $31: 30$ \\
\hline Montagem (cliente) - $\mathrm{h}$ & $6: 00$ & 3:00 & 7:00 & $7: 00$ & $23: 00$ \\
\hline \multicolumn{6}{|c|}{ Mês Referência: Janeiro/2019 } \\
\hline Características & $\begin{array}{r}\text { Projeto } 1 \\
\text { Quarto }\end{array}$ & $\begin{array}{r}\text { Proje } \\
\text { Qua }\end{array}$ & & $\begin{array}{l}\text { rojeto 3: } \\
\text { Cozinha }\end{array}$ & $\begin{array}{l}\text { Total } \\
\text { Mês }\end{array}$ \\
\hline \multicolumn{6}{|l|}{ Tipo do Orçamento } \\
\hline $\begin{array}{l}\text { Projeto próprio }(\mathrm{h}) \\
\text { Projeto de arquitetos } \\
\text { Cor da Chapa }\end{array}$ & $1: 25$ & $\begin{array}{r}0: 4 \\
-\end{array}$ & & $\begin{array}{c}1: 00 \\
-\end{array}$ & $3: 10$ \\
\hline Chapa cor clara & 1 & 1 & & 1 & 3 \\
\hline $\begin{array}{l}\text { Chapa cor escura } \\
\text { Tipo Peças }{ }^{*}\end{array}$ & 1 & 1 & & 1 & 3 \\
\hline Peças retas até $30 \mathrm{~cm}$ & 44 & 4 & & 22 & 70 \\
\hline Peças retas $30 \mathrm{~cm}$ a $1 \mathrm{~m}$ & 92 & 34 & & 76 & 202 \\
\hline Peças retas $1 \mathrm{~m}$ a $2 \mathrm{~m}$ & 12 & 2 & & 17 & 31 \\
\hline Peças retas acima de $2 \mathrm{~m}$ & 13 & 5 & & - & 18 \\
\hline $\begin{array}{l}\text { Peças chapa dupla (reforçada) até } \\
30 \mathrm{~cm}\end{array}$ & 2 & - & & - & 2 \\
\hline $\begin{array}{l}\text { Peças chapa dupla (reforçada) } 30 \\
\mathrm{~cm} \text { a } 1 \mathrm{~m}\end{array}$ & 9 & - & & 18 & 27 \\
\hline $\begin{array}{l}\text { Peças chapa dupla (reforçada) } 1 \mathrm{~m} \\
\text { a } 2 \mathrm{~m}\end{array}$ & 9 & 1 & & 1 & 11 \\
\hline $\begin{array}{l}\text { Peças chapa dupla (reforçada) } \\
\text { acima de } 2 \mathrm{~m}\end{array}$ & 10 & 6 & & 5 & 21 \\
\hline $\begin{array}{l}\text { SUBTOTAL } \\
\text { Pré-Montagem e Montagem }\end{array}$ & 191 & 52 & & 139 & 382 \\
\hline Pré-montagem (empresa) - $\mathrm{h}$ & $10: 30$ & $4: 2$ & & 9:00 & $23: 50$ \\
\hline Montagem (cliente) - $\mathrm{h}$ & $13: 30$ & 4:0 & & $8: 30$ & $26: 00$ \\
\hline
\end{tabular}


Também foram cronometrados os tempos médios para a fabricação de cada tipo de peça utilizada por cada móvel, segregado por fase/etapa do processo produtivo, e atribuídos graus de dificuldade para a sua execução, os quais são definidos com base na experiência do marceneiro, no que tange a interferência de cada peça em seu trabalho, ao considerar alguns fatores de maior complexidade. Esse detalhamento está descrito nos tópicos a seguir, cuja segmentação respeita as macro etapas identificadas na Figura 1.

\subsection{Fase de elaboração do orçamento}

A Tabela 2 apresenta os resultados de tempo e grau de dificuldade para a fase de orçamento dos móveis produzidos em outubro de 2018 e janeiro de 2019, ou seja, já contempla os somatórios de todos os móveis produzidos.

A coluna denominada "total de projetos" se refere ao número de peças/trabalhos executados no mês. Conta-se, também, os tempos e o graus de dificuldades unitários, cuja multiplicação pelo total de projetos resulta no tempo total de fabricação e no grau de dificuldade total. Especificamente para essa fase do processo produtivo, não há o detalhamento do tempo unitário, visto que não há uma padronização dos processos. Assim, apenas foram cronometrados os tempos de elaboração em cada projeto/móvel, conforme já demonstrado na Tabela 1.

Tabela 2

Dados de tempo e grau de dificuldade da fase de orçamento

\begin{tabular}{lccccc}
\hline Características & $\begin{array}{c}\text { Total } \\
\text { Projetos } \\
\text { Mês }\end{array}$ & $\begin{array}{c}\text { Tempo por } \\
\text { Unidade } \\
\text { (Min.) }\end{array}$ & $\begin{array}{c}\text { Total } \\
\text { Horas Mês }\end{array}$ & $\begin{array}{c}\text { Grau de Dificuldade } \\
\text { por Unidade } \\
\text { (De 1 a 5) }\end{array}$ & $\begin{array}{c}\text { Grau de } \\
\text { Dificuldade } \\
\text { Total }\end{array}$ \\
\hline Fase 1: Orçamento 102018 & $\mathbf{4}$ & - & $\mathbf{3 : 5 0 : 0 0}$ & $\mathbf{4}$ & $\mathbf{4}$ \\
Projeto próprio & 4 & - & $3: 50: 00$ & 1 & 4 \\
Projeto de arquitetos & 0 & - & - & 3 & 0 \\
\hline Fase 1: Orçamento 012019 & $\mathbf{3}$ & - & $\mathbf{3 : 1 0 : 0 0}$ & $\mathbf{4}$ & $\mathbf{3}$ \\
Projeto próprio & 3 & - & $3: 10: 00$ & 1 & 3 \\
Projeto de arquitetos & 0 & - & - & 3 & 0 \\
\hline
\end{tabular}

Nota. Fonte: Elaborado com base nos dados da pesquisa.

$\mathrm{Na}$ fase do orçamento foram considerados dois tipos de projetos: o elaborado pelo próprio marceneiro e o projetado por arquiteto contratado pelo cliente. O projeto realizado pelo marceneiro tem um grau de dificuldade menor, por conhecer todos os detalhes e especificações do móvel e do ambiente onde será entregue, porém, 
demanda mais tempo, pois requer a elaboração do desenho. Por outro lado, nos projetos elaborados pelo arquiteto, o grau de dificuldade é considerado maior, visto que, além de ter um layout mais complexo, o marceneiro não tem total conhecimento da área de montagem do móvel e, principalmente, das suas particularidades.

\subsection{Fase de corte}

Ao dar sequência ao processo produtivo, a Tabela 3 apresenta 0 detalhamento de tempo e de grau de dificuldade para a segunda fase das macro etapas definidas a partir do fluxograma (Figura 1), que se refere ao corte das peças.

Tabela 3

Dados de tempo e grau de dificuldade na fase de corte

\begin{tabular}{|c|c|c|c|c|c|}
\hline Características* & $\begin{array}{c}\text { Total } \\
\text { Projetos } \\
\text { Mês }\end{array}$ & $\begin{array}{l}\text { Tempo } \\
\text { por } \\
\text { Unidade } \\
\text { (Min.) }\end{array}$ & $\begin{array}{c}\text { Total } \\
\text { Horas } \\
\text { Mês }\end{array}$ & $\begin{array}{c}\text { Grau de } \\
\text { Dificuldade } \\
\text { por Unidade } \\
(1-5)\end{array}$ & $\begin{array}{c}\text { Grau de } \\
\text { Dificuldade } \\
\text { Total }\end{array}$ \\
\hline Fase 2: Corte 10/2018 & 405 & 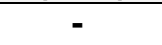 & 9:17:30 & 89 & 993 \\
\hline Peças retas até $30 \mathrm{~cm}$ & 124 & 0:00:30 & $1: 02: 00$ & 4 & 496 \\
\hline Peças retas $30 \mathrm{~cm}$ a $1 \mathrm{~m}$ & 192 & 0:01:00 & $3: 12: 00$ & 1 & 192 \\
\hline Peças retas $1 \mathrm{~m}$ a $2 \mathrm{~m}$ & 18 & 0:02:00 & $0: 36: 00$ & 1 & 18 \\
\hline Peças retas acima de $2 \mathrm{~m}$ & 4 & 0:03:00 & $0: 12: 00$ & 5 & 20 \\
\hline Peças em grau $30 \mathrm{~cm}$ a $1 \mathrm{~m}$ & 3 & 0:02:00 & 0:06:00 & 5 & 15 \\
\hline $\begin{array}{l}\text { Peças em sequência do desenho da chapa } \\
30 \mathrm{~cm} \text { a } 1 \mathrm{~m}\end{array}$ & 4 & 0:01:00 & 0:04:00 & 4 & 16 \\
\hline Peças chapa dupla (reforçada) $30 \mathrm{~cm}$ a $1 \mathrm{~m}$ & 29 & $0: 02: 30$ & $1: 12: 30$ & 4 & 116 \\
\hline Peças chapa dupla (reforçada) $1 \mathrm{~m}$ a $2 \mathrm{~m}$ & 8 & 0:05:00 & 0:40:00 & 4 & 32 \\
\hline Peças chapa dupla (reforçada) acima de $2 \mathrm{~m}$ & 19 & 0:07:00 & 2:13:00 & 4 & 76 \\
\hline Chapa cor clara & 2 & - & - & 1 & 2 \\
\hline Chapa cor escura & 2 & - & - & 5 & 10 \\
\hline Fase 2: Corte 01/2019 & 388 & - & $10: 24: 50$ & 89 & 865 \\
\hline Peças retas até $30 \mathrm{~cm}$ & 70 & 0:00:30 & 0:35:00 & 4 & 280 \\
\hline Peças retas $30 \mathrm{~cm}$ a $1 \mathrm{~m}$ & 202 & 0:01:00 & $3: 22: 00$ & 1 & 202 \\
\hline Peças retas $1 \mathrm{~m}$ a $2 \mathrm{~m}$ & 31 & 0:02:00 & 1:02:00 & 1 & 31 \\
\hline Peças retas acima de $2 \mathrm{~m}$ & 18 & 0:03:00 & 0:54:00 & 5 & 90 \\
\hline Peças chapa dupla (reforçada) até $30 \mathrm{~cm}$ & 2 & $0: 01: 10$ & 0:02:20 & 4 & 8 \\
\hline Peças chapa dupla (reforçada) $30 \mathrm{~cm}$ a $1 \mathrm{~m}$ & 27 & 0:02:30 & 1:07:30 & 4 & 108 \\
\hline Peças chapa dupla (reforçada) $1 \mathrm{~m}$ a $2 \mathrm{~m}$ & 11 & 0:05:00 & $0: 55: 00$ & 4 & 44 \\
\hline Peças chapa dupla (reforçada) acima de $2 \mathrm{~m}$ & 21 & 0:07:00 & $2: 27: 00$ & 4 & 84 \\
\hline Chapa cor clara & 3 & - & - & 1 & 3 \\
\hline Chapa cor escura & 3 & - & - & 5 & 15 \\
\hline
\end{tabular}

Nota. Fonte: Elaborado com base nos dados da pesquisa ( ${ }^{*}$ Demonstra apenas os itens consumidos).

$\mathrm{Na}$ fase de corte são vários os fatores que podem influenciar no grau de dificuldade de cada tipo de peça. Cita-se, como exemplo, as peças de tamanho pequeno (até $30 \mathrm{~cm}$ ), cuja proximidade com as serras das máquinas provocam um 
alto risco de acidentes de trabalho. Além disso, as peças de ângulos em grau exigem um cuidado maior para que fiquem com o encaixe e desenho correto do MDF. As peças redondas são feitas em uma máquina específica que, também, requerem cuidado no manuseio quanto à segurança e para que tenham uma finalização adequada. Já, as peças em sequências, por exemplo, sequências de gavetas e painéis, requerem cuidado para que o desenho da chapa seja seguido corretamente, pois em alguns casos ocorre que as chapas de MDF escolhidas possuem um sentido de veio, assemelhando-se ao veio de madeira. Outro fator que interfere na complexidade do corte é a cor da chapa, pois peças escuras requerem mais atenção pelo fato de poder deixar marcas durante o seu manuseio.

\subsection{Fase de colagem}

Ainda, quanto ao levantamento de tempo de produção e grau de dificuldade, parte-se para a análise da fase de colagem, conforme descrito na Tabela 4. 
Tempo e Grau de dificuldade como Critérios de Rateio dos Custos Indiretos na Produção de

Móveis sob Medida

Ana Paula Stuhlert, Altair Borgert, Emanuele Engelage

Tabela 4

Dados de tempo e grau de dificuldade da fase de colagem

\begin{tabular}{|c|c|c|c|c|c|}
\hline Características* & $\begin{array}{c}\text { Total } \\
\text { Projetos } \\
\text { Mês }\end{array}$ & $\begin{array}{l}\text { Tempo } \\
\text { por } \\
\text { Unidade } \\
\text { (Min.) }\end{array}$ & $\begin{array}{c}\text { Total } \\
\text { Horas } \\
\text { Mês }\end{array}$ & $\begin{array}{c}\text { Grau de } \\
\text { Dificuldade } \\
\text { por Unidade } \\
(1-5)\end{array}$ & $\begin{array}{c}\text { Grau de } \\
\text { Dificuldade } \\
\text { Total }\end{array}$ \\
\hline Fase 3: Colagem 10/2018 & 405 & & 5:03:15 & 75 & 934 \\
\hline Peças retas até $30 \mathrm{~cm}$ & 124 & 0:00:30 & $1: 02: 00$ & 2 & 248 \\
\hline Peças retas $30 \mathrm{~cm}$ a $1 \mathrm{~m}$ & 192 & 0:00:45 & $2: 24: 00$ & 2 & 384 \\
\hline Peças retas $1 \mathrm{~m}$ a $2 \mathrm{~m}$ & 18 & 0:01:00 & $0: 18: 00$ & 2 & 36 \\
\hline Peças retas acima de $2 \mathrm{~m}$ & 4 & 0:01:30 & 0:06:00 & 3 & 12 \\
\hline Peças em grau $30 \mathrm{~cm}$ a $1 \mathrm{~m}$ & 3 & $0: 01: 10$ & $0: 03: 30$ & 4 & 12 \\
\hline $\begin{array}{l}\text { Peças em sequência do desenho da chapa } \\
30 \mathrm{~cm} \text { a } 1 \mathrm{~m}\end{array}$ & 4 & 0:00:45 & 0:03:00 & 2 & 8 \\
\hline Peças chapa dupla (reforçada) $30 \mathrm{~cm}$ a $1 \mathrm{~m}$ & 29 & 0:00:50 & $0: 24: 10$ & 4 & 116 \\
\hline Peças chapa dupla (reforçada) $1 \mathrm{~m}$ a $2 \mathrm{~m}$ & 8 & 0:01:10 & 0:09:20 & 4 & 32 \\
\hline Peças chapa dupla (reforçada) acima de $2 \mathrm{~m}$ & 19 & $0: 01: 45$ & $0: 33: 15$ & 4 & 76 \\
\hline Chapa cor clara & 2 & - & - & 1 & 2 \\
\hline Chapa cor escura & 2 & - & - & 4 & 8 \\
\hline Fase 3: Colagem 01/2019 & 388 & & 5:17:35 & 75 & 919 \\
\hline Peças retas até $30 \mathrm{~cm}$ & 70 & 0:00:30 & 0:35:00 & 2 & 140 \\
\hline Peças retas $30 \mathrm{~cm}$ a $1 \mathrm{~m}$ & 202 & 0:00:45 & $2: 31: 30$ & 2 & 404 \\
\hline Peças retas $1 \mathrm{~m}$ a $2 \mathrm{~m}$ & 31 & 0:01:00 & 0:31:00 & 2 & 62 \\
\hline Peças retas acima de $2 \mathrm{~m}$ & 18 & $0: 01: 30$ & 0:27:00 & 3 & 54 \\
\hline Peças chapa dupla (reforçada) até $30 \mathrm{~cm}$ & 2 & 0:00:30 & 0:01:00 & 4 & 8 \\
\hline Peças chapa dupla (reforçada) $30 \mathrm{~cm}$ a $1 \mathrm{~m}$ & 27 & 0:00:50 & $0: 22: 30$ & 4 & 108 \\
\hline Peças chapa dupla (reforçada) $1 \mathrm{~m}$ a $2 \mathrm{~m}$ & 11 & 0:01:10 & $0: 12: 50$ & 4 & 44 \\
\hline Peças chapa dupla (reforçada) acima de $2 \mathrm{~m}$ & 21 & $0: 01: 45$ & $0: 36: 45$ & 4 & 84 \\
\hline Chapa cor clara & 3 & - & - & 1 & 3 \\
\hline Chapa cor escura & 3 & - & - & 4 & 12 \\
\hline
\end{tabular}

Nota. Fonte: Elaborado com base nos dados da pesquisa ( ${ }^{*}$ Demonstra apenas os itens consumidos).

$\mathrm{Na}$ fase da colagem, as peças retas e em sequência possuem um grau de dificuldade menor, visto que é realizada em uma máquina própria para essa função. Entretanto, as peças de ângulo em grau e redondas precisam ser coladas manualmente, o que requer um cuidado adicional. Já, as peças de chapa dupla podem ser coladas na máquina, mas é preciso ter controle e precisão maior para que não seja necessário refazer o processo. Nessa fase, a cor da chapa tem grande importância, pois interfere no tipo de cola utilizada. Enquanto a chapa MDF de cor clara utiliza cola branca, cuja colagem é mais rápida e fácil de manusear, as chapas que possuem cor escura necessitam de cola incolor, que requer cuidado para não gerar manchas, além de ter um tempo de secagem maior. 


\subsection{Fase de limpeza das peças}

Após o corte e a colagem, conforme demonstrado no fluxograma (Figura 1), passa-se para a fase de limpeza. Da mesma forma, apresenta-se na Tabela 5 os dados de tempo e grau de dificuldade para a limpeza das peças produzidas em outubro de 2018 e janeiro de 2019.

Tabela 5

Dados de tempo e grau de dificuldade da fase da limpeza

\begin{tabular}{|c|c|c|c|c|c|}
\hline Características* & $\begin{array}{c}\text { Total } \\
\text { Projetos } \\
\text { Mês }\end{array}$ & $\begin{array}{c}\text { Tempo } \\
\text { por } \\
\text { Unidade } \\
\text { (Min.) }\end{array}$ & $\begin{array}{c}\text { Total } \\
\text { Horas } \\
\text { Mês }\end{array}$ & $\begin{array}{c}\text { Grau de } \\
\text { Dificuldade } \\
\text { por Unidade } \\
(1-5)\end{array}$ & $\begin{array}{c}\text { Grau de } \\
\text { Dificuldade } \\
\text { Total }\end{array}$ \\
\hline Fase 4: Limpeza 10/2018 & 405 & - & 6:19:10 & 62 & 534 \\
\hline Peças retas até $30 \mathrm{~cm}$ & 124 & 0:00:40 & $1: 22: 40$ & 1 & 124 \\
\hline Peças retas $30 \mathrm{~cm}$ a $1 \mathrm{~m}$ & 192 & 0:00:50 & $2: 40: 00$ & 1 & 192 \\
\hline Peças retas $1 \mathrm{~m}$ a $2 \mathrm{~m}$ & 18 & 0:01:30 & $0: 27: 00$ & 1 & 18 \\
\hline Peças retas acima de $2 \mathrm{~m}$ & 4 & 0:02:00 & 0:08:00 & 2 & 8 \\
\hline Peças em grau $30 \mathrm{~cm}$ a $1 \mathrm{~m}$ & 3 & $0: 02: 00$ & 0:06:00 & 4 & 12 \\
\hline $\begin{array}{l}\text { Peças em sequência do desenho da chapa } \\
30 \mathrm{~cm} \text { a } 1 \mathrm{~m}\end{array}$ & 4 & 0:00:50 & 0:03:20 & 1 & 4 \\
\hline Peças chapa dupla (reforçada) $30 \mathrm{~cm}$ a $1 \mathrm{~m}$ & 29 & $0: 01: 10$ & $0: 33: 50$ & 3 & 87 \\
\hline Peças chapa dupla (reforçada) $1 \mathrm{~m}$ a $2 \mathrm{~m}$ & 8 & 0:01:45 & 0:14:00 & 3 & 24 \\
\hline Peças chapa dupla (reforçada) acima de $2 \mathrm{~m}$ & 19 & 0:02:20 & $0: 44: 20$ & 3 & 57 \\
\hline Chapa cor clara & 2 & - & - & 1 & 2 \\
\hline Chapa cor escura & 2 & - & - & 3 & 6 \\
\hline Fase 4: Limpeza 01/2019 & 388 & - & $6: 38: 55$ & 62 & 534 \\
\hline Peças retas até $30 \mathrm{~cm}$ & 70 & 0:00:40 & $0: 46: 40$ & 1 & 70 \\
\hline Peças retas $30 \mathrm{~cm}$ a $1 \mathrm{~m}$ & 202 & $0: 00: 50$ & $2: 48: 20$ & 1 & 202 \\
\hline Peças retas $1 \mathrm{~m}$ a $2 \mathrm{~m}$ & 31 & 0:01:30 & $0: 46: 30$ & 1 & 31 \\
\hline Peças retas acima $2 \mathrm{~m}$ & 18 & 0:02:00 & $0: 36: 00$ & 2 & 36 \\
\hline Peças chapa dupla (reforçada) até $30 \mathrm{~cm}$ & 2 & 0:00:50 & 0:01:40 & 3 & 6 \\
\hline Peças chapa dupla (reforçada) $30 \mathrm{~cm}$ a $1 \mathrm{~m}$ & 27 & 0:01:10 & $0: 31: 30$ & 3 & 81 \\
\hline Peças chapa dupla (reforçada) $1 \mathrm{~m}$ a $2 \mathrm{~m}$ & 11 & $0: 01: 45$ & $0: 19: 15$ & 3 & 33 \\
\hline Peças chapa dupla (reforçada) acima de $2 \mathrm{~m}$ & 21 & 0:02:20 & 0:49:00 & 3 & 63 \\
\hline Chapa cor clara & 3 & - & - & 1 & 3 \\
\hline Chapa cor escura & 3 & - & - & 3 & 9 \\
\hline
\end{tabular}

Nota. Fonte: Elaborado com base nos dados da pesquisa ( ${ }^{*}$ Demonstra apenas os itens consumidos).

De acordo com o marceneiro, a limpeza de peças retas, peças de chapa duplas e peças em sequência possuem grau de dificuldade regular ou moderado. Contudo, as peças de ângulo em grau e as peças redondas, devido ao seu formato, necessitam de cuidado maior no momento da limpeza com a lima, a fim de evitar riscos e outros danos. A cor escura, também, influencia nesse processo e em sua complexidade, pelo risco de manchar a peça com o thinner, que é o produto utilizado para retirada da cola. 
Tempo e Grau de dificuldade como Critérios de Rateio dos Custos Indiretos na Produção de

\subsection{Fase de pré-montagem e montagem}

Por fim, apresenta-se na Tabela 6 os dados de tempo e grau de dificuldade para a última etapa do processo produtivo, a montagem, que se divide em prémontagem e montagem final.

Tabela 6

Dados de tempo e grau de dificuldade da fase de entrega

\begin{tabular}{lccccc}
\hline Características & $\begin{array}{c}\text { Total } \\
\text { Projetos } \\
\text { Mês }\end{array}$ & $\begin{array}{c}\text { Tempo por } \\
\text { Unidade } \\
\text { (Min.) }\end{array}$ & $\begin{array}{c}\text { Total Horas } \\
\text { Mês }\end{array}$ & $\begin{array}{c}\text { Grau de } \\
\text { Dificuldade por } \\
\text { Unidade (1-5) }\end{array}$ & $\begin{array}{c}\text { Grau de } \\
\text { Dificuldade } \\
\text { Total }\end{array}$ \\
\hline Fase 5: Pré-Montagem e & $\mathbf{8}$ & - & $\mathbf{5 4 : 3 0 : 0 0}$ & $\mathbf{5}$ & $\mathbf{2 0}$ \\
Montagem 10/2018 & 4 & - & $31: 30: 00$ & 2 & 8 \\
Pré-Montagem (Empresa) & 4 & - & $23: 00: 00$ & 3 & 12 \\
Montagem (Cliente) & $\mathbf{6}$ & - & $\mathbf{4 9 : 5 0 : 0 0}$ & $\mathbf{5}$ & $\mathbf{1 5}$ \\
\hline Fase 5: Pré-Montagem e & 3 & & $23: 50: 00$ & 2 & 6 \\
Montagem 01/2019 & 3 & & $26: 00: 00$ & 3 & 9 \\
Pré-Montagem (Empresa) & (E) & & & \\
Montagem (Cliente) & & & & &
\end{tabular}

Nota. Fonte: Elaborado com base nos dados da pesquisa.

Destaca-se que, assim como para o orçamento, a montagem não ocorre de forma padronizada em peças específicas, pois é realizada para o móvel como um todo e, portanto, não há o detalhamento de tempo unitário. O tempo total demonstrado na Tabela 6 é calculado pela soma dos tempos cronometrados de cada móvel montado no mês, conforme apresentado na Tabela 1 (Formulários).

Na fase da pré-montagem, ainda na empresa, é realizada a montagem parcial do móvel para que sejam realizados os ajustes finais como, por exemplo, a inserção de puxadores, dobradiças, parafusos e outros acessórios que o compõe. Já, a montagem final ocorre quando o móvel é entregue completo ao cliente.

\subsection{Rateio dos custos indiretos e apuração dos resultados}

Com a apuração dos dados junto aos marceneiros, solicitou-se à contabilidade, por intermédio do auxiliar administrativo, os relatórios de gastos relativos aos dois meses analisados, os quais são descritos na Tabela 7. 
Tabela 7

Gastos da empresa em outubro de 2018 e janeiro de 2019

\begin{tabular}{lcc}
\hline Gastos & Outubro (2018) & Janeiro (2019) \\
\hline Materiais secundários & 996,90 & $1.135,40$ \\
Madeira & 150,00 & 165,00 \\
Cola & 29,90 & 29,90 \\
Parafuso & 297,00 & 312,00 \\
Thinner & 50,00 & 52,50 \\
Dobradiça & 413,00 & 510,00 \\
Acessórios & 57,00 & 66,00 \\
Afiação facas e serras & 70,00 & 60,00 \\
Equipamentos & 330,00 & 470,00 \\
Energia elétrica & 312,40 & 305,25 \\
Combustível & 230,00 & 260,00 \\
Água & 51,20 & 56,80 \\
Extintor & 45,00 & - \\
Salário & 954,00 & 998,00 \\
Pró-labore & $2.330,40$ & $2.330,40$ \\
Total & $\mathbf{5 . 3 1 9 , 9 0}$ & $\mathbf{5 . 6 1 5 , 8 5}$ \\
\hline
\end{tabular}

Nota. Fonte: Elaborado com base nos dados da pesquisa.

Todos os gastos descritos na Tabela 7 são tratados como gastos indiretos, haja vista que, devido às particularidades e cultura da empresa, não é possível realizar os controles e a mensuração exata do consumo por peça ou por móvel. Dessa forma, os gastos indiretos incluem: faturas de água e energia elétrica; combustível; depreciação e manutenção de equipamentos; salário do funcionário que auxilia o marceneiro; pró-labore do proprietário; materiais secundários, como madeira utilizada para compor alguns móveis, parafusos, cola, thinner (solvente utilizado para retirar a cola durante a fase da limpeza), dobradiças e outros acessórios utilizados na fabricação dos móveis. Após apurar os valores totais desses itens, realizou-se o rateio para cada móvel pelos critérios de horas trabalhadas (tempo) e grau de dificuldade (esforço de produção).

Além desses, alguns custos são controlados e apropriados diretamente a cada móvel, como: chapas de MDF, fitas de borda, calceiros, puxadores, vidros, espelhos e outros acessórios.

Dados os custos diretos e indiretos, a Tabela 8 apresenta um resumo da distribuição desses custos para os produtos, com a utilização do critério "tempo". Também, demonstra-se os preços de venda e o lucro bruto de cada móvel em cada mês, dado pelo confronto entre receitas e custo total. Salienta-se que a Tabela 8 utiliza os dados e formatos do Formulário de Coleta (Tabela 1) e das Planilhas de 
Tempo e Grau de dificuldade como Critérios de Rateio dos Custos Indiretos na Produção de Móveis sob Medida Ana Paula Stuhlert, Altair Borgert, Emanuele Engelage

Dados (Tabelas 2 a 6) onde constam todas as fases do processo produtivo (destacadas pela mesma cor de suas tabelas de referência).

Tabela 8

Percepção do custo pelo critério de tempo

\begin{tabular}{|c|c|c|c|c|c|}
\hline \multicolumn{6}{|c|}{ Percepção do Custo pelo Critério de Tempo 10/2018 } \\
\hline & $\begin{array}{l}\text { Projeto 1: } \\
\text { Cozinha }\end{array}$ & $\begin{array}{l}\text { Projeto 2: } \\
\text { Sala }\end{array}$ & $\begin{array}{l}\text { Projeto 3: } \\
\text { Cozinha }\end{array}$ & $\begin{array}{l}\text { Projeto 4: } \\
\text { Cozinha }\end{array}$ & Total Mês \\
\hline Fase 1: Orçamento & 0:45:00 & 0:35:00 & $1: 20: 00$ & 1:10:00 & $3: 50: 00$ \\
\hline Fase 2: Corte Das Peças & 1:49:30 & $1: 45: 30$ & $2: 47: 30$ & $2: 55: 00$ & $9: 17: 30$ \\
\hline Fase 3: Colagem & $0: 55: 50$ & $0: 43: 20$ & $1: 40: 20$ & 1:43:45 & 5:03:15 \\
\hline Fase 4: Limpeza & 1:09:45 & 0:56:05 & $2: 04: 55$ & 2:08:25 & $6: 19: 10$ \\
\hline Fase 5: Pré-Montagem e Montagem & 13:00:00 & 7:30:00 & $17: 00: 00$ & 17:00:00 & $54: 30: 00$ \\
\hline Total (Horas) & 17:40:05 & $11: 29: 55$ & 24:52:45 & 24:57:10 & 78:59:55 \\
\hline Custo Indireto $(R \$)$ & $1.189,80$ & 774,34 & $1.675,40$ & $1.680,36$ & $5.319,90$ \\
\hline Custo Direto $(\mathrm{R} \$)$ & $1.040,00$ & 580,00 & $2.020,00$ & $1.830,00$ & $5.470,00$ \\
\hline Custo Total (R\$) & $2.229,80$ & $1.354,34$ & $3.695,40$ & $3.510,36$ & $10.789,90$ \\
\hline $\begin{array}{l}\text { Preço de Venda realizado pela } \\
\text { Empresa (R\$) }\end{array}$ & $4.000,00$ & $2.500,00$ & $6.500,00$ & $6.000,00$ & $19.000,00$ \\
\hline $\begin{array}{l}\text { Lucro Bruto (R\$) } \\
\text { (\%) do Custo Indireto de cada }\end{array}$ & $1.770,20$ & $1.145,66$ & $2.804,60$ & $2.489,64$ & $8.210,10$ \\
\hline $\begin{array}{l}\text { projeto com relação ao Custo } \\
\text { Indireto Total } \\
\text { (\%) do Lucro Bruto com relação ao }\end{array}$ & $22,37 \%$ & $14,56 \%$ & $31,49 \%$ & $31,59 \%$ & $100,00 \%$ \\
\hline $\begin{array}{l}\text { Preço de Venda } \\
\text { (\%) do Custo Total com relação ao }\end{array}$ & $44,26 \%$ & $45,83 \%$ & $43,15 \%$ & $41,49 \%$ & $43,21 \%$ \\
\hline Preço de Venda & $55,74 \%$ & $54,17 \%$ & $56,85 \%$ & $58,51 \%$ & $56,79 \%$ \\
\hline \multicolumn{6}{|c|}{ Percepção do Custo pelo Critério de Tempo 01/2019 } \\
\hline & $\begin{array}{l}\text { Projeto 1: } \\
\text { Quarto }\end{array}$ & $\begin{array}{l}\text { Projeto 2: } \\
\text { Quarto }\end{array}$ & $\begin{array}{l}\text { Projeto 3: } \\
\text { Cozinha }\end{array}$ & - & Total Mês \\
\hline Fase & $1: 25: 00$ & 0:45:00 & $0: 00$ & - & 3:10:00 \\
\hline Fase 2: Corte Das Peças & 5:16:50 & $1: 42: 00$ & $6: 00$ & - & $10: 24: 50$ \\
\hline Fase 3: Colagem & 2:39:00 & $0: 48: 40$ & 1:49:55 & - & $5: 17: 35$ \\
\hline Fase 4: Limpeza & 3:21:15 & & & - & $6: 38: 55$ \\
\hline Fase 5: Pré-Montagem e Montagem & 24: & $8: 2$ & :00 & - & 49:50:00 \\
\hline Total & $36: 42: 05$ & $12: 35: 25$ & :50 & - & $75: 21: 20$ \\
\hline Custo Indire & $2.735,16$ & 938,29 & $1.942,40$ & - & $5.615,85$ \\
\hline Custo Direto $(\mathrm{R} \$)$ & $2.792,00$ & 973,00 & $1.343,00$ & - & $5.108,00$ \\
\hline Custo Total (R\$) & $5.527,16$ & $1.911,29$ & $3.285,40$ & - & $10.723,85$ \\
\hline $\begin{array}{l}\text { Preço de Venda realizado pela } \\
\text { Empresa }(R \$)\end{array}$ & $9.900,00$ & $3.700,00$ & $5.700,00$ & - & $19.300,00$ \\
\hline $\begin{array}{l}\text { Lucro Bruto (R\$) } \\
\text { (\%) do Custo Indireto de cada }\end{array}$ & $4.372,84$ & $1.788,71$ & $2.414,60$ & - & $8.576,15$ \\
\hline $\begin{array}{l}\text { projeto com relação ao Custo } \\
\text { Indireto Total }\end{array}$ & $48,70 \%$ & $16,71 \%$ & $34,59 \%$ & - & $100,00 \%$ \\
\hline $\begin{array}{l}\text { (\%) do Lucro Bruto com relação ao } \\
\text { Preço de Venda } \\
\text { (\%) do Custo Total com relacão ao }\end{array}$ & $44,17 \%$ & $48,34 \%$ & $42,36 \%$ & - & $44,44 \%$ \\
\hline Preço de Venda & $55,83 \%$ & $51,66 \%$ & $57,64 \%$ & & $55,56 \%$ \\
\hline
\end{tabular}

Nota. Fonte: Elaborado com base nos dados da pesquisa. 
Para o cálculo, informou-se o tempo padrão de fabricação de cada peça em sua determinada fase (orçamento, corte, colagem, limpeza e montagem), sendo que essas fases, também, são segregadas por projeto/móvel. Para chegar à quantidade total das horas por projeto, somou-se o tempo das cinco fases. A partir do saldo total das horas, realizou-se o rateio dos gastos indiretos proporcionalmente às horas dedicadas a cada projeto. Por fim, somou-se o valor dos custos indiretos atribuídos com o valor do custo direto para se obter o custo total de cada móvel fabricado. Juntamente com esses valores, apresenta-se o preço de venda atribuído pelo proprietário da empresa (preço de venda praticado) e, a partir desse confronto, calculou-se o lucro que a empresa obteve com cada móvel.

Pode-se observar que o maior lucro bruto, em termos monetários, pertence ao projeto 1 (quarto), fabricado no mês de janeiro de 2019, pois há uma sobra de $R \$$ $4.372,84$, no confronto entre o preço de venda e os custos totais. Contudo, o projeto 2 deste mesmo mês (01/2019) é o que possui maior margem de lucro, pois, do valor total de venda, $48,34 \%$ convertem-se em lucro, e $51,66 \%$ são custos.

Ao considerar os resultados gerais por esse critério de rateio, verifica-se certa congruência nas margens de lucro aplicadas pela empresa entre seus projetos, visto que ao comparar a maior e a menor margem, de ambos os meses, esse percentual varia apenas $6,85 \%$, mantendo-se numa média de $43,83 \%$.

Em contraponto a esses resultados, realiza-se o cálculo do custo de cada projeto ao utilizar como critério de rateio dos custos indiretos o "grau de dificuldade" para a fabricação do móvel, o qual é estimado com base na perspectiva dos marceneiros. Esse critério considera os aspectos conceituais do método UEP, em que se atribui diferentes pesos para custeamento com base no esforço de produção, cuja descrição dos resultados se apresenta na Tabela 9. 
Tempo e Grau de dificuldade como Critérios de Rateio dos Custos Indiretos na Produção de Móveis sob Medida Ana Paula Stuhlert, Altair Borgert, Emanuele Engelage

Tabela 9

Percepção do custo pelo grau de dificuldade

\begin{tabular}{|c|c|c|c|c|c|}
\hline \multicolumn{6}{|c|}{ Percepção do Custo pelo Critério de Grau de Dificuldade 10/2018 } \\
\hline & $\begin{array}{l}\text { Projeto 1: } \\
\text { Cozinha }\end{array}$ & $\begin{array}{l}\text { Projeto 2: } \\
\text { Sala }\end{array}$ & $\begin{array}{l}\text { Projeto 3: } \\
\text { Cozinha }\end{array}$ & $\begin{array}{l}\text { Projeto 4: } \\
\text { Cozinha }\end{array}$ & Total Mês \\
\hline Fase 1: Orçamento & 1 & 1 & 1 & 1 & 4 \\
\hline Fase 2: Corte Das Peças & 168 & 100 & 341 & 384 & 993 \\
\hline Fase 3: Colagem & 166 & 131 & 313 & 324 & 934 \\
\hline Fase 4: Limpeza & 95 & 83 & 177 & 179 & 534 \\
\hline Fase 5: Pré-Montagem e Montagem & 5 & 5 & 5 & 5 & 20 \\
\hline Total & 435 & 320 & 837 & 893 & 2.485 \\
\hline Custo Indireto $(R \$)$ & 931,25 & 685,06 & $1.791,85$ & $1.911,74$ & $5.319,90$ \\
\hline Custo Direto $(R \$)$ & $1.040,00$ & 580,00 & $2.020,00$ & $1.830,00$ & $5.470,00$ \\
\hline Custo Total (R\$) & $1.971,25$ & $1.265,06$ & $3.811,85$ & $3.741,74$ & $10.789,90$ \\
\hline $\begin{array}{l}\text { Preço de Venda realizado pela } \\
\text { Empresa (R\$) }\end{array}$ & $4.000,00$ & $2.500,00$ & $6.500,00$ & $6.000,00$ & $19.000,00$ \\
\hline Lucro Bruto (R\$) & $2.028,75$ & $1.234,94$ & $2.688,15$ & $2.258,26$ & $8.210,10$ \\
\hline $\begin{array}{l}\text { (\%) do Custo Indireto de cada projeto } \\
\text { com relação ao Custo Indireto Total }\end{array}$ & $17,51 \%$ & $12,88 \%$ & $33,68 \%$ & $35,94 \%$ & $100,00 \%$ \\
\hline $\begin{array}{l}\text { (\%) do Lucro Bruto com relação ao } \\
\text { Preço de Venda }\end{array}$ & $50,72 \%$ & $49,40 \%$ & $41,36 \%$ & $37,64 \%$ & $43,21 \%$ \\
\hline $\begin{array}{l}\text { (\%) do Custo Total com relação ao } \\
\text { Preço de Venda }\end{array}$ & $49,28 \%$ & $50,60 \%$ & $58,64 \%$ & $62,36 \%$ & $56,79 \%$ \\
\hline \multicolumn{6}{|c|}{ Percepção do Custo pelo Critério de Grau de Dificuldade 01/2019 } \\
\hline & $\begin{array}{l}\text { Projeto 1: } \\
\text { Quarto }\end{array}$ & $\begin{array}{l}\text { Projeto 2: } \\
\text { Quarto }\end{array}$ & $\begin{array}{l}\text { Projeto 3: } \\
\text { Cozinha }\end{array}$ & - & Total Mês \\
\hline Fase & 1 & 1 & 1 & - & 3 \\
\hline Jas Peças & 47 & 111 & 28 & - & 865 \\
\hline Fase 3: Colagem & 460 & 128 & 331 & - & 919 \\
\hline Fase 4: Limpeza & 268 & 75 & 191 & - & 534 \\
\hline Fase 5: Pré-Montagem e Montagem & 5 & 5 & 5 & - & 15 \\
\hline Total & 1.20 & 320 & 811 & - & 2.336 \\
\hline Custo Indi & 2.89 & 769,29 & $1.949,69$ & - & $5.615,85$ \\
\hline Cust & & 973 & & - & $5.108,00$ \\
\hline Custo Tot & $5.688,87$ & $1.742,29$ & $3.292,69$ & - & $10.723,85$ \\
\hline $\begin{array}{l}\text { Preço de Venda realizado pela } \\
\text { Empresa (R\$) }\end{array}$ & $9.900,00$ & $3.700,00$ & $5.700,00$ & - & $19.300,00$ \\
\hline Lucro Bruto (R\$) & $4.211,13$ & $1.957,71$ & $2.407,31$ & - & $8.576,15$ \\
\hline $\begin{array}{l}\text { (\%) do Custo Indireto de cada projeto } \\
\text { com relação ao Custo Indireto Total }\end{array}$ & $51,58 \%$ & $13,70 \%$ & $34,72 \%$ & - & $100,00 \%$ \\
\hline $\begin{array}{l}\text { (\%) do Lucro Bruto com relação ao } \\
\text { Preço de Venda }\end{array}$ & $42,54 \%$ & $52,91 \%$ & $42,23 \%$ & - & $44,44 \%$ \\
\hline $\begin{array}{l}\text { (\%) do Custo Total com relação ao } \\
\text { Preco de Venda }\end{array}$ & $57,46 \%$ & $47,09 \%$ & $57,77 \%$ & - & $55,56 \%$ \\
\hline
\end{tabular}

Nota. Fonte: Elaborado com base nos dados da pesquisa.

Quanto à apuração do custo pelo grau de dificuldade, a forma de cálculo é basicamente a mesma, onde se somou os custos diretos e indiretos e confrontou-se com o preço de venda para obter o resultado (lucro bruto). Porém, para ratear os custos indiretos, primeiramente, multiplicou-se o peso atribuído, correspondente ao nível de dificuldade de fabricação de cada peça, pela quantidade total dessas peças 
em determinado projeto/móvel. Isso ocorreu em todas as fases de produção (conforme demonstrado nas Tabelas 2 a 6), e permitiu obter o grau de dificuldade total por peça, por fase do processo, por projeto e, também, o total do mês. A partir disso, utilizou-se como base de rateio a proporção do valor total do grau de dificuldade do móvel em cada período.

Apesar de ocorrer variações nos custos e, consequentemente, no lucro de cada projeto em relação ao critério de rateio pelo tempo, o projeto 1 , fabricado em janeiro de 2019, continua sendo o mais lucrativo em termos monetários ( $R \$$ $4.211,13)$. Da mesma forma, o projeto 2 de janeiro de 2019 continua com a maior margem de lucro, sendo que essa se eleva ainda mais pelo critério de grau de dificuldade (esforço de produção) passando a representar $52,91 \%$ da receita.

Como os valores de receita e de custo total dos períodos não se alteram, haja vista que esses são apenas critérios de distribuição dos valores entre os produtos (Borgert \& Silva, 2005), a margem de lucro média, também, é a mesma $(43,83 \%)$. Porém, diante de um critério de rateio alternativo, a distribuição dos custos entre os projetos/móveis modificou-se, o que faz com que a variação entre as margens de lucro individuais seja mais elevada (15,27\%), sendo a maior $52,91 \%$ e a menor 37,64\% (Projeto 4: Cozinha de 10/2018).

Num comparativo dos critérios de rateio, a Tabela 10 apresenta um copilado com ênfase nas seguintes informações: custo indireto, custo total, lucro e percentuais desses em relação ao preço de venda. De forma geral, pode-se ressaltar que, em ambos os meses, ocorreu variação dos custos para cada projeto entre os dois modos de apuração. Entretanto, ao analisá-los individualmente essa variação não foi superior a $12 \%$, visto que a maior mudança é do Projeto 1: Cozinha, de outubro de 2018 , que passou de um custo total de $R \$ 2.229,80$, pelo critério de tempo, para $R \$ 1.971,25$, pelo critério de esforço de produção (- $R \$ 258,55 ; 11,60 \%)$. Nota-se, ainda, que o Projeto 3: Cozinha, de janeiro de 2019, é o item que possui menor variação de custo e, consequentemente, de lucro, entre os critérios, com variação apenas de $R \$ 7,29$.

Também, pode-se verificar que, apesar dessas variações, em ambos os critérios de rateio, a ordem de produtos se mantem, do maior para o menor custo indireto: (i) Projeto 1: Quarto (01/2019); (ii) Projeto 3: Cozinha (01/2019); (iii) Projeto 4: Cozinha (10/2018); (iv) Projeto 3: Cozinha (10/2018); (v) Projeto 1: Cozinha 
(10/2018); (vi) Projeto 2: Quarto (01/2019) e (vii) Projeto 2: Sala (10/2018). Isso indica que, apesar dos critérios de rateio evidenciarem custos individuais distintos, há certa congruência e similaridade entre eles. Para o custo total, essa ordem, também, é a mesma, com exceção do Projeto 3: Cozinha (10/2018) que passa a ser o segundo item mais caro, o que ocorre em função do montante de custo direto ( $R \$$ $2.020,00)$.

Além disso, conforme já mencionado, a maior e a menor margem de lucro são as mesmas para os dois critérios de rateio, o que fornece indícios de que o critério alternativo proposto no presente estudo (grau de dificuldade) possui semelhanças financeiras (monetária e percentual) com o tempo de produção que é um critério comumente utilizado no Custeio por Absorção. 
Tabela 10

\section{Custo pelo grau de dificuldade}

\begin{tabular}{|c|c|c|c|c|c|c|c|c|}
\hline & & \multicolumn{4}{|c|}{$10 / 2018$} & \multicolumn{3}{|c|}{$01 / 2019$} \\
\hline & & $\begin{array}{l}\text { Projeto 1: } \\
\text { Cozinha }\end{array}$ & $\begin{array}{l}\text { Projeto 2: } \\
\text { Sala }\end{array}$ & $\begin{array}{c}\text { Projeto 3: } \\
\text { Cozinha }\end{array}$ & $\begin{array}{c}\text { Projeto 4: } \\
\text { Cozinha }\end{array}$ & $\begin{array}{l}\text { Projeto 1: } \\
\text { Quarto }\end{array}$ & $\begin{array}{l}\text { Projeto 2: } \\
\text { Quarto }\end{array}$ & $\begin{array}{l}\text { Projeto 3: } \\
\text { Cozinha }\end{array}$ \\
\hline \multicolumn{2}{|c|}{ Preço de Venda realizado pela Empresa (R\$) } & $4.000,00$ & $2.500,00$ & $6.500,00$ & $6.000,00$ & $9.900,00$ & $3.700,00$ & $5.700,00$ \\
\hline \multirow{3}{*}{ 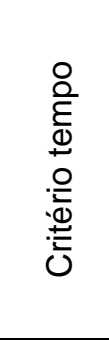 } & Custo Total (R\$) & $2.229,80$ & $1.354,34$ & $3.695,40$ & $3.510,36$ & $5.527,16$ & $1.911,29$ & $3.285,40$ \\
\hline & Lucro Bruto $(\mathrm{R} \$)$ & $1.770,20$ & $1.145,66$ & $2.804,60$ & $2.489,64$ & $4.372,84$ & $1.788,71$ & $2.414,60$ \\
\hline & $\begin{array}{l}\text { (\%) do Lucro Bruto com relação ao Preço de } \\
\text { Venda }\end{array}$ & $44,26 \%$ & $45,83 \%$ & $43,15 \%$ & $41,49 \%$ & $44,17 \%$ & $48,34 \%$ & $42,36 \%$ \\
\hline \multirow{4}{*}{ 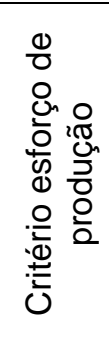 } & Custo Indireto $(\mathrm{R} \$)$ & 931,25 & 685,06 & $1.791,85$ & $1.911,74$ & $2.896,87$ & 769,29 & $1.949,69$ \\
\hline & Custo Total (R\$) & $1.971,25$ & $1.265,06$ & $3.811,85$ & $3.741,74$ & $5.688,87$ & $1.742,29$ & $3.292,69$ \\
\hline & Lucro Bruto $(\mathrm{R} \$)$ & $2.028,75$ & $1.234,94$ & $2.688,15$ & $2.258,26$ & $4.211,13$ & $1.957,71$ & $2.407,31$ \\
\hline & $\begin{array}{l}\text { (\%) do Lucro Bruto com relação ao Preço de } \\
\text { Venda }\end{array}$ & $50,72 \%$ & $49,40 \%$ & $41,36 \%$ & $37,64 \%$ & $42,54 \%$ & $52,91 \%$ & $42,23 \%$ \\
\hline \multirow{2}{*}{ 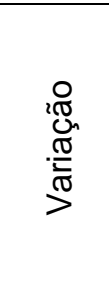 } & $\begin{array}{l}\text { (\%) do Lucro Bruto com relação ao Preço de } \\
\text { Venda }\end{array}$ & $-6,46 \%$ & $-3,57 \%$ & $1,79 \%$ & $3,85 \%$ & $1,63 \%$ & $-4,57 \%$ & $0,13 \%$ \\
\hline & $\begin{array}{l}\text { (\%) do Custo Total com relação ao Preço de } \\
\text { Venda }\end{array}$ & $6,46 \%$ & $3,57 \%$ & $-1,79 \%$ & $-3,85 \%$ & $-1,63 \%$ & $4,57 \%$ & $-0,13 \%$ \\
\hline
\end{tabular}

Nota. Fonte: Elaborado com base nos dados da pesquisa. 
Por fim, analisou-se, também, as diferenças de operacionalização entre os critérios, a fim de se ter uma visão comparativa mais ampla. Dessa forma, de acordo com os apontamentos do sócio proprietário e do seu auxiliar de marcenaria, houve certa dificuldade durante o mapeamento dos dados pelo critério de tempo de fabricação, visto que as informações requeridas exigiam controles e anotações no decorrer de suas atividades, o que, por vezes, resultou na interrupção do processo produtivo. Já, a demanda informacional dos graus de dificuldade requisitou certo tempo de análise inicial para estabelecimento das equivalências, mas que, dadas as características operacionais, tendem a se perpetuar ao longo do tempo, com pouca variação ou até mesmo mantendo-se inalterados.

\section{CONCLUSÃO}

O presente estudo analisou os custos de fabricação de móveis sob medida, de uma microempresa, localizada na cidade de Rio do Sul, em Santa Catarina, por meio do Custeio por Absorção, utilizando-se como critérios de rateio o "tempo" (horas trabalhadas) e o "grau de dificuldade" (esforço de produção), com ponderações quanto às suas semelhanças e particularidades.

A importância dessa análise justifica-se, primeiramente, pela necessidade de identificar os custos de produção em empresas cujas características dos produtos são particularizadas, pois ocorrem por encomenda, como é o caso dos móveis projetados. Esse conhecimento é parte importante na definição de estratégias e, principalmente, para precificação, a fim de realizar orçamentos adequados e dentro das expectativas de retorno dos proprietários. Além disso, este estudo possibilitou comparar dois critérios distintos para rateio dos custos indiretos: um que requer a apuração de tempos de produção; e outro que se baseia na experiência do proprietário, que também é marceneiro. Assim, pode-se analisar em que pontos há diferenças e similaridades nas formas de cálculo e compreender como isso pode interferir na operacionalização do cálculo de custo, no processo de elaboração do orçamento e na formação do preço de venda. 
Tempo e Grau de dificuldade como Critérios de Rateio dos Custos Indiretos na Produção de Móveis sob Medida Ana Paula Stuhlert, Altair Borgert, Emanuele Engelage

Em linhas gerais, pode-se observar que não há grandes variações na percepção dos custos de cada projeto desenvolvido pelos dois critérios analisados e, em ambos, o preço de venda aplicado é coerente com o custo, o que gera uma lucratividade alinhada com as expectativas do gestor (margem de lucro média de $43,83 \%$ ). Além disso, a margem de lucro apresentada por cada móvel fabricado não obteve uma variação superior a $7 \%$ se comparados os diferentes critérios.

Dessa maneira, demonstra-se que o proprietário tem certo controle dos gastos e movimentações da empresa, mesmo sem utilizar métodos específicos de custeio, com controles acurados. Assim, seu conhecimento quanto à complexidade do processo produtivo (grau de dificuldade) pode ser considerado um critério válido para apropriação dos custos, mesmo que subjetivo. Entretanto, alguns relatos do proprietário indicam que a aplicação do Custeio por Absorção, indiferente do critério de rateio utilizado, permitiu maior reflexão sobre as características e o andamento do negócio, auxiliando-o em algumas decisões internas e de mercado. Dentre elas, o proprietário destacou a importância de passar a atribuir alguns gastos diretamente aos produtos, pois, quando esses gastos foram listados detalhadamente, percebeu-se que alguns podem ser melhor controlados, como as dobradiças, parafusos e algumas peças de madeira. Isso apenas demanda maior organização na fábrica, mas como trabalham só em dois, esse controle não é tão difícil e pode resultar em maior exatidão na identificação do custo e do lucro de cada móvel.

Assim, os cálculos realizados e, em especial, o detalhamento proporcionado pode favorecer o gerenciamento, com maior controle e planejamento, inclusive numa perspectiva de médio e longo prazo. Diante disso, conclui-se que, independentemente do critério utilizado para a apuração dos custos indiretos, as duas análises forneceram base informacional para a tomada de decisão. Contudo, quanto à operacionalização das técnicas, o proprietário relata maior facilidade e engajamento com o critério de esforço de produção (grau de dificuldade), pois "a rotina da fábrica, muitas vezes, dificulta o controle exato do tempo, já que tem que cronometrar e anotar a informação 
Tempo e Grau de dificuldade como Critérios de Rateio dos Custos Indiretos na Produção de Móveis sob Medida

Ana Paula Stuhlert, Altair Borgert, Emanuele Engelage

no ato". Essa declaração, justamente, corrobora a validade em termos de uso do grau de dificuldade como critério de rateio dentro do modelo de Custeio por Absorção.

Por fim, o conhecimento das semelhanças e das diferenças entre os critérios, permitiu compreender quais as interferências dessa escolha na elaboração do orçamento e na formação do preço de venda, visto que o custo entre os produtos se altera, mesmo mantendo-se a ordem dos produtos mais caros. Ressalta-se que o proprietário não tinha uma compreensão do custo como uma percepção da realidade, que pode variar em função do método escolhido (Borgert \& Silva, 2005). Porém, após a realização dessas análises, o mesmo declarou ter percebido a importância de se utilizar técnicas específicas e valorizar mais o processo de gestão de custos, o que está alinhado com Bornia (2002).

Cabe destacar que essa pesquisa possui algumas limitações, em especial o fato de a análise ocorrer em uma única empresa, considerada de pequeno porte, que possui apenas dois funcionários em seu processo fabril. Assim, a definição dos graus de dificuldade, os resultados e suas interpretações, limitam-se à percepção desses indivíduos e dos pesquisadores, não podendo ser generalizados para análise e decisões de outras empresas e segmentos.

Diante disso, sugere-se que pesquisas futuras estendam essas análises para outros contextos, com enfoque nos critérios de rateio, seus resultados financeiros e características de implantação, a fim de consolidar critérios que representem a realidade organizacional e que diminuam as críticas quanto à apropriação dos custos indiretos (Schultz et al., 2010), em alternativa àqueles já consolidados.

\section{REFERÊNCIAS}

Abbas, K., Gonçalves, M. N., \& Leoncine, M. (2012). Os métodos de custeio: vantagens, desvantagens e sua aplicabilidade nos diversos tipos de organizações apresentadas pela literatura. Contexto - Revista do Programa de Pós-Graduação em Controladoria e Contabilidade da UFRGS, 12(22), 145-159. 
Tempo e Grau de dificuldade como Critérios de Rateio dos Custos Indiretos na Produção de Móveis sob Medida

Ana Paula Stuhlert, Altair Borgert, Emanuele Engelage

Belli, A. P., Andruchechen, J. R., \& Richartz, F. (2013). Estruturação de um sistema de custeio híbrido em uma empresa prestadora de serviços de colheita florestal. Custos e @gronegócio Online, 9(3), 174-195.

Borgert, A., \& Silva, M. Z. (2005). Método de custeio híbrido para gestão de custos de uma empresa prestadora de serviços. Congresso Brasileiro de Custos, Florianópolis, SC, Brasil, 9.

Bornia, A. C. (2002). Análise gerencial de custos: aplicação em empresas modernas. Porto Alegre: Bookman.

De Lima, S. R., \& Thomaz, J. L. P. (2020). Gestão de custos aplicada a serviços de saúde: um estudo na implantação do custeio por absorção nos serviços de tomografia de um hospital do Vale do Paranhana no Rio Grande do Sul. Revista de Auditoria Governança e Contabilidade, 8(37), 112-126.

Faria, B. C., Vale, J. W. S. P. D., Facin, A. L. F., \& de Carvalho, M. M. (2020). Principais desafios na identificação e mensuração dos custos indiretos em projetos: um estudo de múltiplos casos. Gestão \& Produção, 27(1), 1-19.

Freitas, M. M., Borgert, A.; \& Flach, L. (2016). Análise do custo médio por um método híbrido do $A B C$ e UEP em uma empresa australiana que opera em modalidade de home office. Revista de Contabilidade da UFBA, 10(1), 5-19.

Hojna, R., \& Stryckova, L. (2018). Absorption costing analysis and its use by czech manufacturing companies. In 5th International Multidisciplinary Scientific Conference on social sciences and arts SGEM 2018 (pp. 19-26).

Levant, Y., \& Zimnovitch, H. (2013). Contemporary evolutions in costing methods: understanding these trends through the use of equivalence methods in France. Accounting History, 18(1), 51-75.

Machado, A. O., Borgert, A., \& Lunkes, R. J. (2006). ABC e UEP - um ensaio em empresas de software. Congresso Brasileiro de Custos, Belo Horizonte, MG, Brasil, 13.

Martins, F. P., \& de Miranda, A. M. (2020). A contabilidade de custos para determinação do custo de produção do pão francês, pão de queijo e rosca na empresa pão real, baseado no custeio por absorção. QUALIA: a ciência em movimento, 6(1), 50-67.

Mattar, F. N. (2005). Pesquisa de marketing: metodologia e planejamento. (6a ed.). São Paulo: Atlas. 
Morozini, J. F., Cambruzzi, D., \& Balen, F. V. (2009). Unidade de esforço de produção (UEP) como método de custeio: implantação de modelo em uma indústria de laticínios. Revista ABCustos, 4(1), 101-123.

Neves, S., \& Viceconti, P. E. V. (2003) Contabilidade de custos: um enfoque direto e objetivo. (7a ed.). São Paulo: Frase Editora.

Rabelo, E. C., Borgert, A., \& Medeiros, C. S. C. (2009). Apropriação dos custos indiretos de fabricação em indústrias cerâmicas do sul catarinense. Congresso Brasileiro de Custos, Fortaleza, CE, Brasil, 16.

Pinto, L., \& Moura, P. (2011). Formação do preço de venda e estratégias de precificação. In: Simpósio de Excelência em Gestão e Tecnologia. Simpósio de Excelência em Gestão e Tecnologia - SEGeT, Resende, RJ, Brasil, 8.

Schultz, C. A., Silva, M. Z., \& Borgert, A. (2010). É o custeio por absorção o único método aceito pela contabilidade? Revista Brasileira de Contabilidade, 183(2), 3955.

Severiano Filho, C., \& de Melo, J. F. M. (2006). Desmistificando as limitações do uso do custeio por absorção. Contabilidade Vista \& Revista, 17(3), 11-24.

Silva, M. Z., Borgert, A., \& Schultz, C. A. (2009). Sistematização de um método de custeio híbrido para o custeamento de procedimentos médicos: uma aplicação conjunta das metodologias ABC e UEP. Revista de Ciências da Administração, 11(23), 217-244.

Yin, R. K. (2005). Estudo de caso: planejamento e métodos. (3a ed.). Porto Alegre: Bookman.

Data de Submissão: 28/02/2020

Data de Aceite: 09/04/2021 